\title{
PERCEPÇÃO DE EQUIPES DE SAÚDE BUCAL NO NORTE DE MINAS GERAIS SOBRE A FORMAÇÃO DE TÉCNICOS EM SAÚDE BUCAL DO SUS
}

\author{
VIEWS OF ORAL HEALTH TEAMS IN NORTHERN MINAS GERAIS ON THE TRAINING OF NHS ORAL \\ HEALTH TECHNICIANS
}

PERCEPCIÓN DE LOS EQUIPOS DE SALUD ORAL EN EL NORTE DE MINAS GERAIS SOBRE LA FORMACIÓN DE TÉCNICOS EN SALUD ORAL DEL SUS

\author{
Maria Patrícia da Silva ${ }^{1}$ \\ Geórgia Sarmento Costa ${ }^{2}$ \\ Zaida Angela Marinho de Paiva Crispim ${ }^{3}$ \\ Eveline Andries Castro ${ }^{4}$ \\ Marília Borborema Rodrigues Cerqueira ${ }^{5}$ \\ Elika Garibalde ${ }^{6}$
}

Resumo A inclusão das Equipes de Saúde Bucal na Estratégia Saúde da Família representa uma mudança na saúde pública. Este estudo tem como objetivo conhecer percepções de egressos e coordenadores da formação técnica ministrada pela Escola Técnica de Saúde para Técnicos em Saúde Bucal em municípios do Norte de Minas Gerais, a partir do Programa Brasil Sorridente. A metodologia utilizada é exploratória-descritiva, com ênfase qualitativa. Os egressos afirmam que a participação no curso beneficia o serviço prestado à população por meio de ações de educação em saúde, maior eficiência, compreensão e qualidade de atividades desenvolvidas nas clínicas. As falas dos coordenadores e dos egressos enfatizam as melhorias nas ações de biossegurança. A percepção das equipes de saúde bucal, representada pelos egressos do curso técnico em saúde bucal e pelos coordenadores das equipes em que estão inseridos, ratifica a hipótese de que investir em educação para os trabalhadores do Sistema Único de Saúde contribui para a qualidade do serviço prestado.

Palavras-chave equipes de saúde bucal; técnicos em saúde bucal; Sistema Único de Saúde.

\begin{abstract}
The inclusion of Oral Health Teams in the Family Health Strategy represents a shift in public health. This study aims to get to know the views of graduates and coordinators of the technical training provided by the Technical Health School for Oral Health Technicians in municipalities in Northern Minas Gerais based on the Smiling Brazil Program. The methodology that was used is exploratory and descriptive, with a qualitative emphasis. The graduates claim that taking the course benefits the service provided to the population through actions in health education, it affords greater efficiency and understanding, and improves the quality of activities done in clinics. Coordinators and graduates emphasize the improvements that take place in biosecurity actions. The perception of the oral health teams, represented by the graduates of the technical course in oral health and by the coordinators of the teams in which they were in, confirms the hypothesis that investing in education for Unified Health System workers helps improve service quality.
\end{abstract}

Keywords oral health teams; oral health technicians; Unified Health System. 


\section{Introdução}

Os debates nacionais sobre a saúde bucal não são recentes. Pode-se dizer que, mesmo antes das reivindicações do movimento pela Reforma Sanitária, esta era uma questão importante para a saúde pública no Brasil (Zanetti, 1996; Narvai, 1994; Espoti, 2007).

Em 1986, aconteceu a I Conferência Nacional de Saúde Bucal, no mesmo ano em que ocorreu a VIII Conferência Nacional de Saúde. Sobre essa integração, Espoti (2007) analisa da seguinte forma: a odontologia, ao fazer parte desse movimento maior da saúde, buscou, por meio de sujeitos engajados, romper com o caráter mercantilista, trazendo à tona o conceito de saúde bucal. Assim, o principal objetivo era a expansão da atenção em saúde bucal não só em quantidade, mas em qualidade - e, ainda mais, a adequação dos recursos humanos para efetivar a integração entre saúde bucal e saúde geral do indivíduo.

Apesar de a criação do Sistema Único de Saúde (SUS), com a Constituição de 1988, ser uma grande conquista do movimento pela Reforma Sanitária, no âmbito da saúde bucal não houve grandes avanços, até que em 2000 (12 anos depois da criação jurídica do SUS) foram estabelecidas as Equipes de Saúde Bucal no Programa Saúde da Família (PSF), por meio da portaria GM/MS n. 1.444/2000.7 O que chama a atenção é o fato de que as reivindicações só começaram a ser implementadas nos anos 2000. Eram demandas que já existiam na agenda do movimento pela Reforma Sanitária desde os anos 1970.

O que sempre existiu foi exclusão na área dos cuidados odontológicos, sendo possível confirmá-la nos números da Pesquisa Nacional por Amostra de Domicílios (PNAD), divulgada em 2000, a qual revelou que mais de 30 milhões de brasileiros nunca tinham ido ao dentista. Tal fato reforça ainda mais a necessidade de se aumentarem as ações de prevenção e de se garantirem os investimentos na área curativa em procedimentos odontológicos. Nesse sentido, o Ministério da Saúde propôs como estratégia de reorganização da Atenção Básica à Saúde a inclusão de Equipes de Saúde Bucal no PSF (Brasil, 2002). Com a inclusão de Equipes de Saúde Bucal no PSF, foram definidas duas possíveis modalidades de inserção: a modalidade I, composta pelo cirurgião-dentista e o auxiliar de consultório dentário (ACD); e a modalidade II, formada por um cirurgião-dentista, um ACD e um técnico em higiene dental (THD). 8

As ações do Ministério da Saúde em torno da inclusão efetiva das Equipes de Saúde Bucal nos PSFs traz um novo cenário para os técnicos em saúde bucal e os auxiliares de saúde bucal, que veem abertas novas possibilidades de trabalho. Soma-se a tal fato a regulamentação da profissão dos técnicos em saúde bucal, que aconteceu em 2008, por meio da lei n. 11.889/2008. 
Para Bezerra (2007), a legitimação profissional deve-se ao papel exercido pelo SUS, que trouxe uma nova perspectiva na consolidação legal da profissão, observando-se a intensificação da formação e contratação, a partir da inclusão das Equipes de Saúde Bucal no PSF, iniciada em 2000. Além disso, a aprovação da lei n. 11.889/2008 pode ser considerada como um importante marco regulatório, que há muito tempo se esperava. A fixação de competências nessa lei representa um ganho e uma conquista para os trabalhadores da área, ao mesmo tempo que significa um avanço na ampliação do acesso aos serviços odontológicos. Tal fato, algo muito esperado pela categoria, abre perspectivas promissoras para a organização sindical dos auxiliares e técnicos em saúde bucal. Também merece atenção o fato de reforçar o trabalho em equipe (Frazão e Narvai, 2011).

Nesse contexto de transformações e avanços, uma nova demanda se apresenta aos profissionais dessa área. É preciso ter formação e qualificação específicas para o trabalho nos serviços públicos e a própria certificação para aqueles que trabalhavam sem a devida formação técnica. Não seria qualquer forma de educação profissional, mas aquela voltada para as ações orientadas a um trabalho de equipe, em que a prevenção e a promoção prevalecem em detrimento de ações isoladas de cura, em que o trabalho de um único sujeito, o dentista, cede lugar ao trabalho da equipe de saúde bucal.

A questão referente à qualificação desses profissionais é comum em todo o país. Queluz (2005) confirma que profissionais auxiliares e técnicos em odontologia frequentemente sofrem com problemas como falta de habilitação específica, o que culmina na reduzida filiação ao Conselho Regional de Odontologia. Sales et al. (2007) chamam a atenção para o problema referente à formação dos profissionais auxiliares do cirurgião-dentista no estado da Paraíba, onde 54,2\% foram treinados no próprio consultório odontológico, enquanto $45,8 \%$ receberam treinamento em cursos formais.

Esses dados evidenciam que trabalhador técnico e auxiliar da área de odontologia apresentam uma trajetória bem parecida à dos técnicos e auxiliares de enfermagem. Esta é uma característica comum entre outros profissionais de nível médio da saúde que também convivem com a ausência da formação técnica formal. Tais trabalhadores são fundamentais para o serviço, mas em algumas situações sofrem com preconceito e pouco reconhecimento da importância de seu trabalho no SUS.

A implementação da Política Nacional de Saúde Bucal (Brasil Sorridente), em 2004, fez emergir compromissos baseados em pressupostos para reorientar o modelo de atenção em saúde bucal. Entre eles, destacam-se: a busca pela qualificação da atenção básica, garantindo qualidade e resolutividade, independentemente da estratégia adotada pelo município para sua organização; o conhecimento dos resultados das ações de saúde bucal por meio de indicadores adequados, o que implica a existência de registros fáceis, 
confiáveis e contínuos; a implementação de uma política de educação permanente para os trabalhadores em saúde bucal, no intuito de fazer a diferença e trazer mudanças na formação técnica, de graduação e pós-graduação, que atendam às reais necessidades da população e sigam os princípios do SUS; e, ainda, a realização de estudos que possam investigar os principais problemas relativos à saúde bucal, bem como expandir as ações dos serviços públicos de saúde bucal em todos os níveis de atenção (Brasil, 2004).

A partir das ações do Ministério da Saúde com a inclusão de profissionais como técnicos em saúde bucal e auxiliares de saúde bucal, melhor dizendo, a inserção de Equipes de Saúde Bucal na Estratégia Saúde da Família, o trabalho odontológico apresenta uma dimensão de saúde coletiva, com ênfase na importância de seu papel na construção desse conceito social de saúde, que fundamenta as diretrizes do SUS. A Escola Técnica de Saúde da Universidade Estadual de Montes Claros (Unimontes), uma das instituições formadoras da Rede de Escolas Técnicas do SUS, em 2007 e 2008 ofereceu o curso de Educação Profissional Técnica de Nível Médio em Saúde Bucal. Assim, a formação técnica desses profissionais deve considerar essa nova dimensão do trabalho: formar uma dimensão crítico-reflexiva que compreenda a importância das ações desenvolvidas na atenção básica e na saúde bucal, para a melhoria de indicadores de saúde e a qualidade da assistência. Nesse sentido, o estudo apresenta como objetivo principal conhecer resultados da formação técnica ministrada pela Escola Técnica de Saúde para Técnicos em Saúde Bucal em municípios do Norte de Minas Gerais, ação realizada por meio da parceria entre Ministério da Saúde e Escola Técnica de Saúde/Unimontes, a partir do Programa Brasil Sorridente.

\section{Metodologia}

A metodologia utilizada é de cunho exploratório-descritivo, 9 em uma perspectiva qualitativa. Segundo Haguette (1999, p. 63), “os métodos qualitativos enfatizam as especificidades de um fenômeno em termos de suas origens e de sua razão de ser". As abordagens qualitativas não se preocupam em fixar leis, produzir teorias ou generalizações. Os dados qualitativos permitem conhecer o fenômeno estudado e não têm expressividade numérica.

Para Minayo e Sanches (1993), a abordagem qualitativa se firma no campo da subjetividade e do simbolismo.

Definir o nível simbólico, dos significados e da intencionalidade, constituí-lo como um campo de investigação e atribuir-lhe um grau de sistematicidade pelo desenvolvimento do método e técnicas têm sido as tarefas e os desafios dos cientistas 
sociais que trabalham com a abordagem qualitativa ao assumirem as críticas interna e externa exercidas sobre suas investigações (Minayo e Sanches, 1993, p. 245).

A coleta das informações na construção deste trabalho foi realizada a partir da adoção das seguintes estratégias: consulta aos documentos da secretaria escolar da ETS/Unimontes, revisão da bibliografia referente ao tema e realização de entrevistas semiestruturadas.

A entrevista semiestruturada permite maior interação com o entrevistado. As questões não são fechadas, possibilitando ao pesquisador obter dados de maneira flexível. Lunardelo (2004) afirma que, com esse meio, é possível articular o direcionamento da entrevista com questões formuladas, como também abordar o tema de maneira livre e reflexiva e obter dados fundamentais sobre o objeto de estudo.

Minayo (2008) pondera que a entrevista é uma conversa a dois, ou entre vários interlocutores, direcionada pela iniciativa do entrevistador, com intuito de construir informações pertinentes para o objeto de pesquisa. “A entrevista semiestruturada combina perguntas fechadas e abertas, em que o entrevistado tem a possibilidade de discorrer sobre o tema em questão sem se prender à indagação formulada" (Minayo, 2008, p. 261).

A análise das entrevistas foi direcionada pela 'análise qualitativa temática', que retirou das respostas expressões principais. Posteriormente, as expressões foram agrupadas em tipos com respostas comuns, que a equipe chamou de ideia principal presente naquelas respostas. Por fim, procedeu-se à quantificação de vezes que cada ideia principal foi encontrada nas falas dos abordados, para assim desvendar e narrar as percepções.

\section{Local de estudo e amostra}

A realização da atividade aconteceu em municípios que são sede de microrregião, integrantes da Macrorregião Norte de Minas Gerais. Os municípios foram: Coração de Jesus, Bocaiuva, Francisco Sá,10 Janaúba, Januária, Montes Claros, Pirapora e Salinas, sede de microrregiões que compõem a Macrorregião Norte de Minas Gerais, conforme estabelecido pela Secretaria de Estado de Saúde de Minas Gerais.

Para seleção da amostra, além dos oito municípios-sede de microrregiões, segundo a Secretaria de Estado de Saúde de Minas Gerais, foram definidos outros dois critérios: os técnicos e auxiliares deveriam residir no município-sede da microrregião onde aconteceu o curso; os trabalhadores abordados deveriam estar trabalhando no SUS, nas Equipes de Saúde Bucal dos respectivos municípios.

Assim, cabe informar que os entrevistados não foram todos os egressos que concluíram o curso. Ponderando que alguns não residiam no município-sede 
e outros não trabalhavam no SUS, também houve casos de técnicos que não foram localizados e, por fim, aqueles abordados pela pesquisa que não se dispuseram a responder. Ao todo, foram abordados 47 técnicos em saúde bucal e nove coordenadores de equipes de saúde bucal. Em Montes Claros, a equipe de pesquisa conseguiu entrevistar três coordenadores. Para cada coordenador participar da pesquisa, seguiu-se o seguinte critério: ele deveria ter trabalhado com os egressos (técnicos de saúde bucal) antes e depois da conclusão do curso técnico (Quadro 1).

\section{Quadro 1}

Quantitativo de alunos do Curso de Educação Profissional Técnica de Nível Médio em Saúde Bucal - Turmas 2007/2008 no Norte de Minas Gerais*

\begin{tabular}{|c|c|c|c|c|c|}
\hline Município-sede & $\begin{array}{l}\text { Matriculados } \\
\text { residentes nas sede } \\
\text { de microrregiões }\end{array}$ & Concluintes & Entrevistados & Municípios de abrangência & Turmas \\
\hline Bocaiuva & 20 & 13 & 10 & $\begin{array}{l}\text { Bocaiuva; Claro dos Poções; Engenheiro Navarro; } \\
\text { Francisco Dumont; Guaraciama; Olhos d'Água }\end{array}$ & 1 \\
\hline Coração de Jesus & 18 & 15 & 2 & $\begin{array}{c}\text { Coração de Jesus; São João do Pacuí; São João da } \\
\text { Lagoa; Lagoa dos Patos; Jequitaí }\end{array}$ & 1 \\
\hline Janaúba & 28 & 25 & 14 & $\begin{array}{c}\text { Janaúba; Porteirinha; Jaíba; Riacho dos Machados; } \\
\text { Verdelândia }\end{array}$ & 1 \\
\hline Januária & 14 & 12 & 3 & $\begin{array}{l}\text { Januária; Cônego Marinho; Brejo do Amparo; Bonito } \\
\text { de Minas; Pedras de Maria da Cruz }\end{array}$ & 1 \\
\hline $\begin{array}{l}\text { Montes Claros } \\
\text { (Francisco Sá) }{ }^{* *}\end{array}$ & $\begin{array}{c}24 \\
4\end{array}$ & $\begin{array}{l}18 \\
-\end{array}$ & $\begin{array}{l}7 \\
1\end{array}$ & $\begin{array}{l}\text { Montes Claros; Francisco Sá; Glaucilândia; Juramento; } \\
\text { Capitão Enéas }\end{array}$ & 1 \\
\hline Pirapora & 15 & 14 & 7 & $\begin{array}{c}\text { Pirapora; Buritizeiro;Várzea da Palma; Ibiaí; } \\
\text { Ponto Chique }\end{array}$ & 1 \\
\hline Salinas & 16 & 16 & 3 & $\begin{array}{l}\text { Salinas; Curral de Dentro; Novo Horizonte; Fruta de } \\
\text { Leite; Rubelita; Padre Carvalho; Santa Cruz de Salinas; } \\
\text { Coronel Murta }\end{array}$ & 1 \\
\hline Totais & 139 & $113^{* * *}$ & 47 & - & 7 \\
\hline
\end{tabular}

Fonte: Secretaria Escolar CEPT/ETS/Unimontes, 2010.

*Em cada turma havia um total de 40 alunos.

**Os alunos do município de Francisco Sá estudaram na sede da Escola Técnica de Saúde do Centro de Educação Profissional e Tecnológica da Unimontes em Montes Claros, Minas Gerais. Francisco Sá também é uma sede de microrregião no Norte de Minas Gerais, apesar de os alunos terem realizado o curso em Montes Claros; logo, foram sete turmas, mas oito sedes de microrregião contempladas com o curso foram abordadas pela pesquisa.

***Importante destacar que, desse total de 113 concluintes, existem técnicos em saúde bucal que não estão inseridos nos serviços do SUS, portanto não eram alvo da pesquisa. 
A seleção da amostragem não foi orientada por critérios numéricos. Como afirma Espoti (2007), em um trabalho norteado por metodologia qualitativa a amostra ideal é aquela que permite visualizar a realidade em suas várias dimensões.

Para melhor compreensão do primeiro critério de seleção da amostra, cabe esclarecer que, no desenvolvimento do curso de Educação Profissional Técnica de Nível Médio em Saúde Bucal e Qualificação Profissional de Nível Médio de Auxiliar de Saúde Bucal, as atividades administrativo-pedagógicas ocorreram de maneira centralizada em Montes Claros, na Escola Técnica de Saúde/Unimontes. Porém, o processo de ensino-aprendizagem se deu em diversos municípios, considerados pela escola como sedes ou núcleos descentralizados, onde o curso foi ministrado. Os alunos de municípios vizinhos participavam das aulas nos municípios-sede.

Os sujeitos abordados na coleta de dados eram trabalhadores das Equipes de Saúde Bucal - auxiliares e técnicos de saúde bucal - egressos da turma que concluiu o curso em 2008. Os coordenadores de Equipes de Saúde Bucal, indicados pelos secretários municipais de saúde, também participaram da pesquisa. Importante dizer que, para que os coordenadores pudessem participar do estudo, deviam estar trabalhando com os técnicos abordados.

\section{A coleta de dados: o trabalho de campo}

O trabalho foi institucionalizado e aprovado pelo Comitê de Ética da Universidade Estadual de Montes Claros, conforme processo n. 1969/10, e pelo Conselho de Extensão, Ensino e Pesquisa (Cepex) da Unimontes, conforme resolução n. 258. Ao longo de todo o trabalho, buscou-se respeitar a autonomia dos indivíduos abordados, pois foram consultados e informados do direito de participar ou não, como de desistir de fazê-lo a qualquer momento.

No período de setembro de 2010 a janeiro de 2011 , foram realizadas visitas às cidades-sede de microrregiões do Norte de Minas Gerais: Bocaiuva, Coração de Jesus, Francisco Sá, Janaúba, Januária, Pirapora e Salinas. No município de Montes Claros, em razão do período de férias de alguns funcionários e de algumas mudanças que ocorreram na Secretaria Municipal de Saúde, não foi possível a coleta de dados no mês de janeiro, já que muitos trabalhadores têm contrato temporário, renovado a cada início de ano. Logo, em Montes Claros só foi possível realizar a coleta de dados em fevereiro de 2011.

No que diz respeito às informações coletadas com os coordenadores, indicados pelos secretários municipais de saúde, em cada município foi abordado um coordenador, exceto em Montes Claros, onde em razão da maior quantidade de Equipes de Saúde Bucal e da distribuição dos egressos/profissionais inseridos nos serviços, foram abordados três coordenadores. 
Importante ressaltar que a equipe, após vários contatos, não conseguiu coletar dados com o coordenador geral das Equipes de Saúde Bucal do município de Coração de Jesus.

\section{Análise de dados: conhecendo a percepção das equipes de saúde bucal sobre resultados da formação técnica na qualidade dos serviços}

Para a análise dos dados, primeiramente foram transcritas as respostas dos sujeitos abordados, um a um. Cada sujeito foi numerado. Em um segundo momento, após leitura e análise de cada resposta individual, foram retiradas as expressões principais de cada resposta e agrupadas em blocos, sendo que as expressões foram agrupadas por tipo de temas comuns. Importante dizer que em algumas falas foi possível identificar mais de uma expressão principal. Ao identificar o número de vezes que uma ideia apareceu nas falas dos técnicos e coordenadores, foi possível descrever e quantificar o que aquele grupo considera em suas percepções sobre os resultados da formação técnica ministrada pela Escola Técnica de Saúde para Técnicos em Saúde Bucal em municípios do Norte de Minas Gerais, ação realizada por meio da parceria entre Ministério da Saúde e Escola Técnica de Saúde/Unimontes.

As entrevistas dos egressos foram analisadas em primeiro lugar, e só em seguida a equipe analisou as respostas dos coordenadores das Equipes de Saúde Bucal onde o egresso estava trabalhando (na data da entrevista).

$\mathrm{Na}$ discussão dos resultados que serão apresentados a seguir com alguns depoimentos, para melhor identificação das falas, os depoentes serão identificados como Egresso 1; em seguida, E-2, E-3 e assim por diante. E, para as falas dos coordenadores das equipes de saúde bucal, será utilizada para o primeiro a identificação Coordenador 1: em seguida, C-2, C-3 e assim por diante.

\section{Resultados e discussão}

A inclusão das Equipes de Saúde Bucal na Estratégia Saúde da Família é significativa e representa um avanço na saúde pública. A lógica do trabalho no SUS, seguindo os preceitos da atenção primária, prevê uma reorganização das práticas do processo de trabalho e, consequentemente, orientação das atividades da equipe. Nesse contexto, o trabalho deve ser norteado para a promoção, a prevenção e a recuperação da saúde bucal.

O principal foco da análise aqui apresentada é conhecer a percepção da Equipe de Saúde Bucal sobre a importância da formação técnica para o desenvolvimento do serviço. 


\section{A percepção dos egressos}

Aos técnicos egressos foi perguntado sobre a importância de participar de um curso técnico para o trabalho e quais os resultados da formação, além do que mudou no trabalho, após a formação técnica. Ao analisar as falas dos egressos, constatou-se que $61,70 \%$ entendem a importância de participar do curso técnico como uma forma de adquirir conhecimentos para melhorar o serviço prestado em atividades de prevenção, promoção e curativas. Como resultado da participação no curso, identifica-se uma contribuição qualitativa no serviço prestado à população. Apreende-se uma noção de coletividade, reconhecida pelos egressos, quando discorrem sobre a importância do conhecimento para o desenvolvimento do trabalho. Além disso, os egressos demonstram, por meio das expressões-chave, que percebem uma dimensão social do trabalho que exercem.

Nesta análise, ressalta-se a relação estabelecida entre educação e trabalho, pois o discurso da maioria dos sujeitos abordados revela que, ao aprender a teoria, as técnicas, ao adquirir conhecimento, o principal resultado é a melhoria da prática, conforme se observa nas palavras dos sujeitos abordados:

(...) adquirir conhecimentos para melhorar o serviço prestado, beneficiar qualitativamente a população (Egresso 1).

É de suma importância, uma vez que qualificados tem-se um maior embasamento científico na realização das ações, programando e realizando com mais eficiência e qualidade o serviço, melhorando a qualidade de vida dos usuários (E-2).

O técnico é mais habilitado para várias atividades nos procedimentos e pode desenvolver atividades de promoção, prevenção, na comunidade (E-3).

Depreende-se uma dimensão política dessa realização como resultado da formação obtida no curso. Assim, entende-se que a formação técnica é importante, pois interfere na qualidade do serviço prestado, conforme Vasquez (1977):

A teoria em si não transforma o mundo. Pode contribuir para a sua transformação, mas para isso tem que sair de si mesma, e, em primeiro lugar, tem que ser assimilada pelos que vão ocasionar, com seus atos reais, efetivos, tal transformação. Entre a teoria e a atividade prática transformadora se insere um trabalho de educação das consciências, de organização de meios materiais e planos concretos de ação: tudo isso como passagem indispensável para desenvolver ações reais, efetivas. Nesse sentido, uma teoria é prática na medida em que materializa, através de uma série de mediações, o que antes só existia idealmente, como conhecimento da realidade ou antecipação ideal de sua transformação (Vasquez, 1977, p. 206-207). 
De acordo com Hannah Arendt (2006), política não se explica pela diferença entre governantes e governados; é uma ação conjunta, realizada em comum acordo. A política, para essa autora, é reflexo da condição humana, que é plural. O objetivo da política é a garantia da vida no sentido amplo. Dessa forma, percebe-se que a dimensão política percebida no discurso apresentado pelo sujeito egresso do Curso Técnico em Saúde Bucal segue para além da dimensão pedagógica. Conforme Hannah Arendt (2006), a educação possui perspectiva política e não está limitada à questão pedagógica puramente.

Os fins da educação estão articulados à sociedade que se busca empreender. Não são, porém, desinteressados, e sim concretos e marcados pelo seu tempo. A educação possui fins sociais e indica que a possibilidade da educação escolar deve ser um instrumento de atualização da vida social e está no poder de concretizar a interação entre senso comum, conhecimento elaborado e prática (Torres, 2007).

O trabalho em saúde pode ser entendido como uma interferência diária de ações relacionadas à vida humana. Assim, desenvolver um trabalho voltado para a qualidade de vida demanda uma formação consciente do papel que cada trabalhador exerce ao prestar seus serviços à comunidade. No discurso da maioria dos egressos, encontra-se presente tal consciência.

Em um segundo momento, os egressos abordaram os resultados da formação técnica no serviço. Analisando as respostas, prevalecem abordagens à formação técnica com a qualidade de ações educativas em saúde, ministradas nas comunidades onde os egressos trabalham, com incidência de $31,91 \%$. Também está em destaque, com incidência de $29,78 \%$, o discurso sobre resultados da formação no desenvolvimento do trabalho nas clínicas. Há aqueles que afirmam que, após a participação no curso, aconteceram mudanças relacionadas à autonomia e à confiança, aparecendo com uma incidência de $27,66 \%$. Por fim, com menor incidência (10,63\%), os técnicos de saúde bucal ponderam que a mudança está relacionada a um melhor entendimento do trabalho em equipe.

A seguir, registram-se algumas das respostas dos egressos do curso Técnico em Saúde Bucal sobre resultados da formação técnica na qualidade das atividades educativas desenvolvidas.

Sim, me tornei uma pessoa mais comunicativa e capacitada para exercer minha profissão, dou mais palestras, e por isso eu acho muito mais importante (E-4).

Desenvolver educação em Saúde, a forma de como comunicar melhor com o paciente (E-5).

A qualificação técnica tem um importante resultado para maior eficiência, compreensão e qualidade no desenvolvimento das atividades na clínica 
e no consultório, como atividades de biossegurança, ainda na percepção dos egressos:

Importante para um maior entendimento nas ações desenvolvidas, que antes eram feitas de forma mecânica e hoje já são realizadas de maneira mais eficiente, com maior qualidade e maior embasamento (E-6).

Importante, pois traz mais segurança nas ações, maior conhecimento, cuidados com a biossegurança (E-7).

A relação entre qualidade das atividades realizadas e formação técnica, percebida nas falas dos sujeitos abordados, remete a Kuenzer (2008), quando esta autora trata do trabalho intelectual como um movimento do pensamento no pensamento, o pensar que se debruça sobre a prática. E a prática é compreendida e apreendida.

Segundo Kuenzer (2008), as novas exigências do mundo do trabalho na contemporaneidade demandam conhecimento teórico de todo o processo de trabalho. O que era exigido na gestão do trabalho taylorista-fordista baseava-se em um tipo de conhecimento que privilegiava o fragmento. No entanto, o que se exige hoje é que seja contemplada a totalidade do processo de trabalho em suas articulações com a prática social.

Se competência no taylorismo-fordismo era fundamentalmente conhecimento tácito advindo da experiência, e de natureza psicofísica, em face das novas tecnologias passa a significar capacidade de trabalhar intelectualmente, de modo a enfrentar os problemas da prática laboral e social. Para isto, se demanda conhecimento teórico. Esta dimensão da competência é nova, e, por contradição, não atende necessariamente apenas ao capital, uma vez que impacta positivamente a formação dos trabalhadores, em razão do que são geradas novas necessidades relativas à formação dos professores de educação profissional (Kuenzer, 2008, p. 27).

A partir do momento em que o trabalhador realiza a técnica e não compreende sua ação, isso se reflete negativamente no desenvolvimento das atividades, podendo ser considerado como uma grande dificuldade para a qualidade de qualquer serviço.

\section{A percepção dos coordenadores das Equipes de Saúde Bucal sobre resultados da formação técnica na qualidade do serviço}

No sentido de buscar conhecer a percepção da Equipe de Saúde Bucal sobre a importância da formação técnica para o trabalho, identificando os resultados 
sobre a formação ministrada pela Escola Técnica de Saúde, também foram coletadas informações dos coordenadores das Equipes de Saúde Bucal nas quais estão inseridos os egressos/técnicos abordados. Primeiramente, os coordenadores foram questionados sobre a percepção deles acerca da importância da formação técnica dos auxiliares para a qualidade do serviço.

Prevalece entre os coordenadores a constatação de que a participação em curso técnico é importante para melhorar a dinâmica dos procedimentos, o apoio ao cirurgião-dentista, a qualidade das ações, o aumento da resolubilidade e melhoria da qualidade das orientações prestadas aos usuários.

Com certeza, a capacitação dos profissionais melhorou consideravelmente as atividades no serviço, pois o conhecimento faz com que a qualidade das ações aumente e a resolubilidade também (Coordenador 1).

Melhora o atendimento, a produção dos atendimentos clínicos, possibilita a escovação supervisionada nas escolas e aumenta a qualidade das orientações dadas aos usuários (C-2).

Quando solicitados a identificar alguma mudança no desenvolvimento das atividades de trabalho de responsabilidade dos egressos/técnicos em saúde bucal após a conclusão do curso técnico, os coordenadores afirmaram que o principal resultado obtido relaciona-se com o desenvolvimento de um trabalho fundamentado em segurança e compreensão da atividade realizada, comprometimento, interesse e envolvimento nas atividades de trabalho: "Postura profissional, segurança e comprometimento com o trabalho"; "Profissionais mais seguros e comprometidos".

Ainda há também, com uma incidência de $44,44 \%$, os que apontam como principais mudanças após a conclusão do curso a melhoria no manuseio dos instrumentos, um progresso ao realizar atividades de manipulação de materiais e o desenvolvimento das ações de biossegurança. Chama a atenção a ênfase dada pelos egressos/técnicos em saúde bucal e pelos coordenadores das Equipes de Saúde Bucal quando discorrem sobre a qualidade em relação às ações com manuseio de material e à aplicação de ações de biossegurança, percebidas após a conclusão do Curso Técnico em Saúde Bucal.

Nesse sentido, deve-se observar que o trabalho nos consultórios e clínicas odontológicas demanda cuidados de biossegurança, tanto para o usuário quanto para a equipe de trabalho. A questão da biossegurança para o Ministério da Saúde (Brasil, 2001) deve ser foco de formação e treinamentos dos trabalhadores da saúde, voltados para a prevenção:

A cadeia de transmissão de riscos deve ser quebrada o mais precocemente possível (...). A informação e o treinamento dos trabalhadores são componentes im- 
portantes das medidas preventivas relativas aos ambientes de trabalho, particularmente se o modo de executar as tarefas propicia a formação ou a dispersão de agentes nocivos à saúde (...). As estratégias para controle dos riscos devem ser, principalmente, à prevenção (...) (Brasil, 2001, p. 44).

A educação prevista para a saúde bucal deve considerar em suas ações não apenas o cuidado com o tratamento, mas também a prevenção e a promoção da saúde, em um sentido integral. É reconhecido tal significado para o processo de trabalho nos consultórios e clínicas, sendo que estudar biossegurança é conhecimento previsto no Plano de Curso para os Técnicos em Saúde Bucal da ETS/Unimontes.

Ao examinar as respostas dos egressos e dos coordenadores, percebe-se a preocupação com o bom desempenho de atividades voltadas para a biossegurança, o que demonstra que se busca trabalhar as ações com tal cuidado, e o quão tais atividades são importantes para a saúde da equipe, para a saúde do usuário e ainda para os gastos públicos - pois ao ministrar ações com biossegurança pode-se influenciar positivamente na diminuição de contágios com outras doenças.

Quando se refere às atividades da saúde, a falta de uma formação técnica compromete significativamente o cuidado com a vida do cidadão que utiliza os serviços do SUS, e a integralidade do atendimento fica comprometida. A educação para o trabalho em saúde deve ser, sim, uma prioridade nas políticas públicas.

\section{Considerações finais}

A inclusão das Equipes de Saúde Bucal na Estratégia Saúde da Família representa uma mudança na política de saúde para aquela parcela da população que não tinha acesso ao serviço de saúde bucal. A política de saúde bucal inserida no SUS é recente e demanda uma formação específica para o trabalho no SUS - diferente daquela baseada no modelo flexneriano - e para o trabalho em clínicas privadas. Dessa maneira, a formação das Equipes de Saúde Bucal demanda a adoção de uma política de educação permanente como uma estratégia que contemple a integração ensino e serviço e supere treinamentos pontuais.

A educação permanente em saúdell pressupõe uma aprendizagem com base na reflexão crítica do trabalho cotidiano que, por meio da reflexão e avaliação dos atos produzidos no trabalho, busque transformar a prática. Mesmo considerando o papel preponderante de ações de educação permanente para a qualidade do serviço, apenas a implementação de políticas de educação permanente em saúde não transforma todos os problemas existentes no sistema. Não há aqui uma defesa ingênua da educação permanente como redentora 
e transformadora dos serviços de saúde, em que o contexto de trabalho, o contexto social das equipes, fatores reforçadores e a cultura institucional, somados à educação, são pontuais para que aconteça uma transformação.

Um dos significados práticos que há de se considerar, ao defender a implantação efetiva da política de educação permanente nas Equipes de Saúde Bucal, é o fato de que certas dificuldades e problemas do trabalho nem sempre estão previstos no desenvolvimento de um curso técnico. Isso ocorre porque a escola não reproduz todos os problemas do cotidiano de trabalho, por mais problematizadora que sejam as ações pedagógicas do processo de ensino e aprendizagem.

A percepção das Equipes de Saúde Bucal, representada pelos egressos do Curso Técnico em Saúde Bucal, turma 2007/2008, e pelos respectivos coordenadores das equipes onde estão inseridos, ratifica a hipótese de que investir em educação para os trabalhadores inseridos no SUS contribui para a qualidade do serviço prestado à população.

O trabalho em saúde pode ser entendido como uma interferência diária de ações relacionadas à vida humana. Assim, desenvolver um trabalho voltado para a qualidade de vida demanda uma formação consciente do papel que cada trabalhador exerce ao prestar seus serviços à comunidade. E no discurso da maioria dos egressos e dos coordenadores abordados está presente tal consciência sobre a melhoria dos serviços após a conclusão do curso.

\section{Colaboradores}

A primeira autora Maria Patrícia da Silva coordenou a pesquisa, participou de todas as suas etapas, realizou a pesquisa de campo, a análise de dados, bem como a elaboração e a revisão crítica do artigo. Zaida Angela Marinho de Paiva Crispim, Eveline Andries Castro e Marília Borborema Rodrigues Cerqueira participaram da análise de dados e da elaboração do artigo. Geórgia Sarmento Costa participou da coleta de dados na pesquisa de campo, da análise dos dados e na elaboração do artigo. Elika Garibalde participou da pesquisa de campo e da elaboração do artigo. 
Resumen La inclusión de los Equipos de Salud Oral en la Estrategia Salud Familiar representa un cambio en la salud pública. Este estudio tiene como objetivo conocer las percepciones de egresados y coordinadores de la formación técnica impartida por la Escuela Técnica de Salud para Técnicos en Salud Oral en municipios del Norte de Minas Gerais, a partir del Programa Brasil Sonriente. La metodología utilizada es exploratoria y descriptiva, con énfasis cualitativo. Los egresados afirman que la participación en el curso beneficia el servicio prestado a la población mediante acciones de educación en salud, mayor eficiencia, comprensión y calidad de actividades desarrolladas en las clínicas. Las palabras de los coordinadores y de los egresados enfatizan las mejoras en las acciones de bioseguridad. La percepción de los equipos de salud oral, representada por los egresados del curso técnico en salud oral y por los coordinadores de los equipos en que están incluidos, ratifica la hipótesis de que invertir en educación para los trabajadores del Sistema Único de Salud contribuye para la calidad del servicio prestado.

Palabras clave Equipos de salud oral; técnicos en salud oral; Sistema Único de Salud.

\section{Notas}

1 Universidade Estadual de Montes Claros, Montes Claros, Minas Gerais, Brasil. Doutoranda em Ciências Sociais da Universidade do Estado do Rio de Janeiro. <mpvitoriano@yahoo.com.br>

Correspondência: Rua Coronel Celestino, 65, Centro, CEP 39400-514, Montes Claros, Minas Gerais, Brasil.

2 Universidade Estadual de Montes Claros, Montes Claros, Minas Gerais, Brasil. Graduada em Odontologia pela Universidade Estadual de Montes Claros.

<gesarmento@yahoo.com.br>

3 Universidade Estadual de Montes Claros, Montes Claros, Minas Gerais, Brasil. Mestranda em Ensino em Saúde da Universidade Federal dos Vales do Jequitinhonha e do Mucuri, Montes Claros, Minas Gerais, Brasil. <zaidamarinhopaiva@yahoo.com.br>

4 Universidade Estadual de Montes Claros, Montes Claros, Minas Gerais, Brasil. Mestranda em Teoria Psicanalítica da Universidade Federal do Rio de Janeiro. <eveacastro@yahoo.com.br>

5 Universidade Estadual de Montes Claros, Montes Claros, Minas Gerais, Brasil. Doutoranda em Demografia pelo Centro de Desenvolvimento e Planejamento Regional da Universidade Federal de Minas Gerais. <mariliaborborema@yahoo.com.br>

6 Escola Técnica de Saúde do Centro de Educação Profissional e Tecnológica da Universidade Estadual de Montes Claros, Montes Claros, Minas Gerais, Brasil. Especialista em Economia pela Universidade Estadual de Montes Claros.

<elikagaribalde@yahoo.com.br> 
7 A base legal na construção da saúde bucal coletiva no SUS, ou seja, que trata da inserção do técnico em saúde bucal (TSB) no SUS, começa pela portaria n. 1.444/2000. A portaria n. 648/2006, além de estabelecer revisão para organização da Atenção Básica em Saúde para o PSF e o Programa Agentes Comunitários de Saúde (Pacs), definiu também como item necessário a formação de equipes multiprofissionais, as quais incluem: cirurgião-dentista, técnico em higiene dental e auxiliar de consultório dentário, podendo tal iniciativa ser considerada um avanço na inclusão da saúde bucal nas Equipes de Saúde da Família.

8 Com a publicação da lei n. 11.889, de 24 de dezembro de 2008, as denominações auxiliar de consultório dentário e técnico de higiene dental são substituídas por auxiliar de saúde bucal e técnico de saúde bucal, respectivamente.

9 Este trabalho resulta de pesquisa financiada pela Rede Observatório de Recursos Humanos em Saúde (ObservaRH), pelo Ministério da Saúde e pela Organização Pan-Americana da Saúde (Opas), realizada em 2010 e 2011.

10 Cabe esclarecer que, no caso do município de Francisco Sá (sede de microrregião), não houve uma turma descentralizada. Os alunos se deslocavam para estudar no município de Montes Claros, na sede da Escola Técnica de Saúde/Unimontes.

11 Para Ceccim (2005, p. 161), a educação permanente corresponde ao: (...) "processo educativo que coloca o cotidiano do trabalho - ou da formação - em saúde em análise, que se permeabiliza pelas relações concretas que operam realidades e que possibilita construir espaços coletivos para a reflexão e avaliação de sentido dos atos produzidos no cotidiano".

\section{Referências}

ARENDT, Hannah. O que é política?. 6. ed. Rio de Janeiro: Bertrand, 2006.

BEZERRA, Larissa A. M. L. Novas formas de flexibilização dos regimes de trabalho no setor público: um estudo de caso do programa de saúde da família em Araruna em 2003. Universidade Federal da Paraíba, Departamento de Administração, 2007. Disponível em: <www.admpg.com.br/2007/anais/ 2004 /artigos/T03-19.pdf>. Acesso em: 10 maio 2010 .

Ministério da Saúde. Doenças relacionadas ao trabalho: manual de procedimentos para os serviços de saúde. Brasília: Ministério da Saúde, 2001.
Ministério da Saúde. Secretaria executiva. Programa saúde da família: equipes de saúde bucal. Brasília: Ministério da Saúde, 2002.

Ministério da Saúde. Secretaria de Atenção a Saúde. Departamento de Atenção Básica. Coordenação Nacional de Saúde Bucal. Política nacional de saúde bucal. 2004. Disponível em: <http://bvsms.saude.gov.br/ bvs/publicacoes/politica_nacional_brasil_ sorridente.pdf $>$. Acesso em: 1 abr. 2009.

CECCIM, Ricardo Burg. Educação permanente em saúde: desafio ambicioso e necessário. Interface: Comunicação, Saúde e Educação, Botucatu, v. 9, n. 16, set./fev. 2005. 
Disponível em: <www.interface.org.br/ revista16/debatel.pdf $>$. Acesso em: 1 ago. 2007.

ESPOTI, Carolina D. D. A saúde bucal na saúde da família: ação comunicativa de Habermas guiando as relações. 2007. 161f. Dissertação (Mestrado em Saúde Coletiva) Centro de Ciências da Saúde, Universidade Federal do Espírito Santo, Espírito Santo, 2007. Disponível em: <www.dominiopublico.gov.br/ download/texto/cp079497.pdf>. Acesso em: 1 maio 2009.

FRAZÃO, Paulo; NARVAI, Paulo C. Lei n. 11.889/2008: avanço ou retrocesso nas competências do Técnico em Saúde Bucal?. Trabalho, Educação e Saúde, Rio de Janeiro, v. 9, n.1, mar./jun. 2011. Disponível em: $<$ www.scielo.br/pdf/rsp/v40nspe/30633. pdf $>$. Acesso em: 1 maio 2011.

HAGUETTE, Teresa M. F. Metodologias qualitativas na sociologia. 6 ed. Petrópolis: Vozes, 1999.

KUENZER, Acácia Z. Formação de professores para a educação profissional e tecnológica: perspectivas históricas e desafios contemporâneos. In: INSTITUTO NACIONAL DE ESTUDOS E PESQUISAS EDUCACIONAIS ANÍSIO TEIXEIRA (INEP). Formação de professores para Educação Profissional e Tecnológica. Brasília: Instituto Nacional de Estudos e Pesquisas Educacionais Anísio Teixeira, 2008. p. 19-40. (Coleção Educação Superior em Debate; v. 8).

LUNARDELO, Simone R. O trabalho do agente comunitário de saúde nos núcleos de Saúde da Família em Ribeirão Preto, São Paulo. 2004. 156f. Dissertação (Mestrado em Enfermagem) - Universidade de São Paulo, Escola de Enfermagem de Ribeirão Preto, São Paulo, 2004.

MINAYO, Maria Cecília de S.; SANCHES, Odécio. Quantitativo-qualitativo: oposição ou complementaridade?. Cadernos de Saúde Pública, Rio de Janeiro, n. 9, v. 3, p. 239262, jul./set. 1993.
MINAYO, Maria Cecília de S. O desafio do conhecimento: pesquisa qualitativa em saúde. 11. ed. São Paulo: Hucitec, 2008.

NARVAI, Paulo C. Odontologia e saúde bucal coletiva. São Paulo: Hucitec, 1994.

OLIVEIRA, Maria A. de et al. Auxiliar e técnico de saúde bucal: da condição de 'ocupação' ao status de 'profissão' da odontologia. Disponível em: <http://abomg. no-ip.com/abo/pdfs/Artigo_ASB_TSB.pdf $>$. Acesso em: 5 maio 2009.

QUELUZ, Dagmar P. Perfil dos profissionais auxiliares da odontologia e suas implicações no mercado de trabalho. Revista Odonto Ciência, Rio Grande do Sul, v. 20, n. 49, jul./set. 2005. Disponível em: <http:// revistaseletronicas.pucrs.br/ojs/index.php/ fo/article/viewFile/1137/897>. Acesso em: 1 abr. 2009.

RODRIGUES, Luiz Alberto R. A dimensão política em Gramsci e Hannah Arendt: uma tentativa de articulação com a democracia. Trabalho e Educação, Belo Horizonte, v. 17, n. 2, maio/ago., 2008.

SALES, Cristiane V. M. et. al. Delegação de funções ao pessoal auxiliar odontológico pelos cirurgiões-dentistas da cidade de Campina Grande, PB. Revista Ciências Médicas Biológicas, Salvador, v. 6, n. 1, p. 47-53, jan./abr. 2007.

TORRES, Maria L. A formação de profesSores nos ISEs: uma experiência alternativa em questão. 2007. 270 f. Tese (Doutorado em Educação) - Universidade Federal do Rio de Janeiro. Rio de Janeiro, 2007.

VASQUEZ, Adolfo S. Filosofia da práxis. Rio de Janeiro: Paz e Terra, 1977.

Recebido em 11/12/2012

Aprovado em 13/06/2013 